\title{
Capsule Commentary on Shelton et al., Reducing PSA-Based Prostate Cancer Screening in Men $\geq 75$ Years Old with Highly Specific Computerized Clinical Decision Support
}

\author{
Sarah Patricia Slight, $P h D^{1,2}$ \\ 'Center for Patient Safety Research and Practice, Division of General Internal Medicine, Brigham and Women's Hospital, Harvard Medical School, \\ Boston, MA, USA; ${ }^{2}$ School of Medicine, Pharmacy and Health, Durham University, Durham, UK.
}

J Gen Intern Med 30(8):1187

DOI: $10.1007 / \mathrm{s} 11606-015-3286-6$

(๑) Society of General Internal Medicine 2015

C linical decision support (CDS) systems can improve patient safety by providing physicians with important information and guidance at the point of care. This guidance should be evidence-based, and the alert message clear and concise, to allow physicians to directly act on the information received. Shelton et al. develop a highly specific and targeted CDS alert to remind providers of the current guidelines and policy at the point of ordering a screening PSA. ${ }^{1}$ This relatively simple intervention has been shown to significantly reduce inappropriate PSA screening for prostate cancer.

Alerts which lack clinical relevance (low alert specificity) are often overridden by the physician, thus contributing to alert fatigue. ${ }^{2,3}$ The authors of this study reflected on how they used a wide range of structured clinical data (including laboratory, pharmacy, and problem list data) to help increase the specificity of their alert, and believe that this may have contributed to its success. Alert specificity and sensitivity is recognized as being important. ${ }^{4}$ Patient specific parameters, e.g., age, should be incorporated into decision-making algorithms to improve the accuracy and appropriateness of alerts. One study found that only $10 \%$ of drug-drug interaction alerts would be applicable in all circumstances; however, by incorporating laboratory results and other clinical parameters, this percentage could rise to $25 \%$ or possibly higher. ${ }^{5}$ The effectiveness of alerts should always be monitored; this includes how often they fire and whether clinicians choose to accept or override the alerts. Interestingly, Shelton et al. reported sharp increases in screening rates during periods when the alerts were switched off. This finding underscores the importance of CDS as a tool to guide physician decision-making and improve the quality and efficiency of health care. Furthermore, it shows how they can address inappropriate overuse of preventive care and, in turn, reduce health care costs.

Corresponding Author: Sarah Patricia Slight, PhD; Center for Patient Safety Research and Practice, Division of General Internal Medicine, Brigham and Women's Hospital, Harvard Medical School, 1620 Tremont St. 3rd floor, Boston, MA 02120, USA (e-mail: sslight@partners.org).

\section{REFERENCES}

1. Shelton JB, Ochotorena L, Benett C, Shekelle P, Kwan L, Skolarusc T, Goldzweig C. Reducing PSA-based prostate cancer screening in men $\geq 75$ years old with highly specific computerized clinical decision support. J Gen Intern Med. doi: 10.1007/s11606-015-3249-y.

2. Seidling HM, Phansalkar S, Seger DL, Paterno MD, Shaykevich S, Haefeli WE, et al. Factors influencing alert acceptance: a novel approach for predicting the success of clinical decision support. J Am Med Inform Assoc. 2011;18(4):479-84.

3. Taegtmeyer AB, Kullak-Ublick GA, Widmer N, Falk V, Jetter A. Clinical usefulness of electronic drug-drug interaction checking in the care of cardiovascular surgery inpatients. Cardiology. 2012;123(4):219-22.

4. Lapane KL, Waring ME, Schneider KL, Dube C, Guilliam BJ. A mixed method study of the merits of e-prescribing drug alerts in primary care. $J$ Gen Intern Med. 2008;23(4):442-6.

5. Seidling HM, Klein U, Schaier M, Czock D, Theile D, Pruszydlo MG, et al. What, if all alerts were specific - estimating the potential impact on drug interaction alert burden. Int J Med Inform. 2014;83(4):285-91. 